\title{
The Preparation of Metals and Alloys for Backscatter Electron Imaging
}

James H. Steele Jr. Ph.D. Consultant, 2019 Nova Road, Pine, CO 80470

Observation of microstructure using backscatter electron (BSE) contrast requires distinctly different preparation than is normally used to provide contrast for optical observation. The requirement for observing backscatter contrast between phases and/or grains is that the surface layer be undeformed, and as smooth as possible. In most cases this means that standard mechanical polishing, when used to prepare a section, be finished with an electro-polishing step. This allows electron channeling contrast (ECC) to be observed in addition to atomic number contrast [1]. 3mm disks that are prepared for TEM examination also make excellent samples for BSE observation of microstructure.

An example of a mechanically polished Bi-Sn alloy cast microstructure is provided in Fig. 1 to illustrate the quality of $\mathrm{z}$-contrast images obtained from a $20 \mathrm{Kv}$ electron beam with normal incidence using a 4-crystal solid state BSE detector. The phases are Bi rich (bright) and Sn rich (dark), which occur as a eutectic mixture, and as Bi rich precipitates within the proeutectic dendrite arms. The contrast between the phases, which have BSE coefficients, $\eta(83)=0.496$, and $\eta(50)=$ 0.417 , is approximately $18 \%$. The resolution for this $\mathrm{z}$-contrast image is illustrated by the small Bi rich precipitate, which is approximately $50 \mathrm{~nm}$ in size.

An example of an electro-polished sample of two phase 2205 duplex stainless steel as hot rolled is presented in Fig. 2. This microstructure consists of ferrite and austenite layers which have been elongated in the direction of hot rolling. The major contrast is from electron channeling which results in a maximum of about $4 \%$ difference in the backscatter coefficient from different crystallographic orientations [2]. There has been a small electro-etching applied to this sample, which causes the ferrite and austenite to be removed at different rates. This produces steps at the ferrite-austenite phase boundaries that are observed as topographic contrast in the BSE image.

The ferrite phase shows a recrystallized microstructure, whereas the austenite exhibits a recovered microstructure. The resolution of this ECC image can be estimated to be approximately equal to the width of the grain boundaries in the recrystallized ferrite, which is approximately $100 \mathrm{~nm}$.

\section{References}

[1] O. Wells, Scanning Electron Microscopy, Chapter 7, McGraw Hill Inc. NY, 1974

[2] D. L. Davidson, Int. Met. Rev. 29 (1984) 75. 


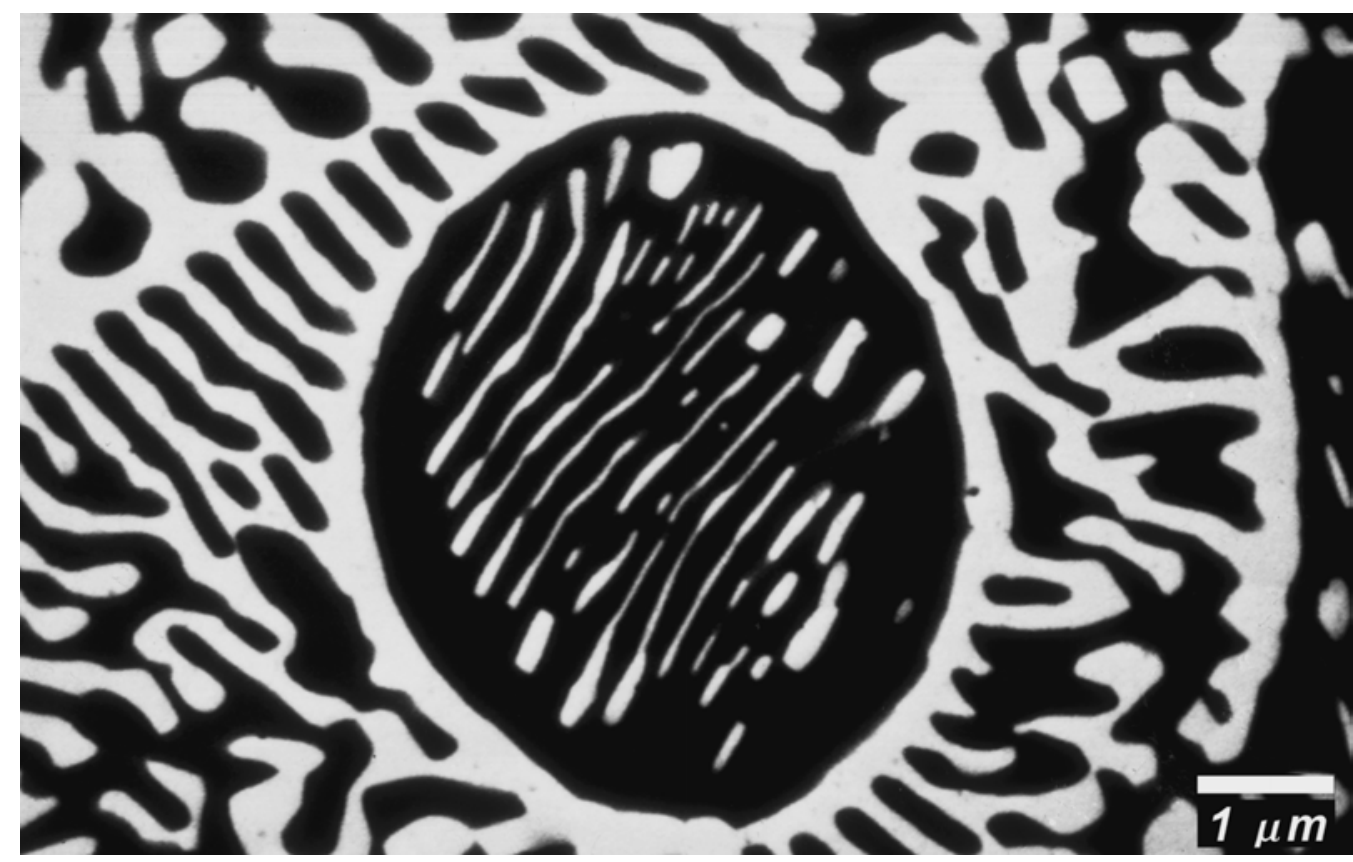

Fig. 1 Z-contrast BSE image of Bi-Sn alloy $(58 \% \mathrm{Sn} / 42 \% \mathrm{Bi})$ showing the Chinese script eutectic consisting of Bi rich (bright) and Sn rich (dark) phases. The rounded feature in the center is a cross section through a proeutectic dendrite arm that contains $\mathrm{Bi}$ rich precipitates.

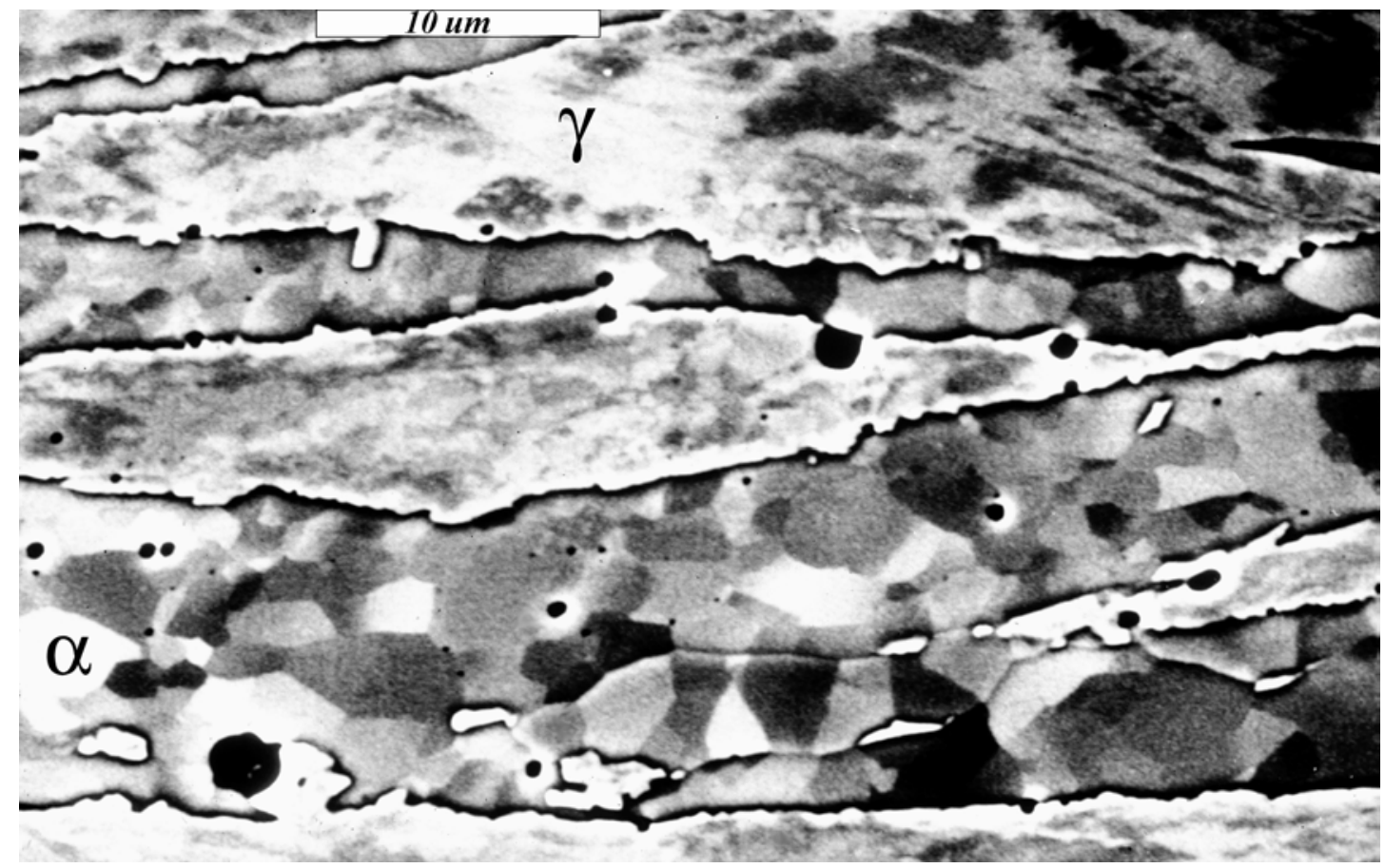

Fig. 2 Electron Channeling contrast image of 2205 Duplex Stainless Steel as hot rolled. Grain structure in the recrystallized ferrite $(\alpha)$ is clearly shown, as well as substructure in the recovered austenite $(\gamma)$. Electro-etching has produced steps at the ferrite-austenite phase boundaries. 